\title{
Dietary-Related Preventative Factors for Breast Cancer: A Case-Control Study from the Mecca Region
}

Deena M. Hasanain

Umm Al-Qura University

Alaa H. Qadhi

Umm Al-Qura University

Khloud J. Ghafouri

Umm Al-Qura University

Wedad F. Azhar

Umm Al-Qura University

Mazen M. Ghaith

Umm Al-Qura University

Hamza M. Assaggaf

UMM: University of Maine at Machias

Maha H. Alhussain

King Saud University

Ahmad A. Alghamdi

Taif University

Mahmoud M. Habibullah

Jazan University

Waleed M. Bawazir

King Abdulaziz University

Firas S. Azzeh ( $\nabla$ fsazzeh@uqu.edu.sa )

Umm Al-Qura University https://orcid.org/0000-0002-1400-5465

\section{Research}

Keywords: Breast cancer, Dietary habits, Postmenopause.

Posted Date: June 2nd, 2021

DOI: https://doi.org/10.21203/rs.3.rs-552428/v1 
License: (c) (i) This work is licensed under a Creative Commons Attribution 4.0 International License. Read Full License 


\section{Abstract}

Background: Breast cancer is one of the leading causes of death worldwide, it affects both males and females. In Saudi Arabia, breast cancer has been the most prevalent type of cancer for the past few years in females. Dietary habits and cultural beliefs vary according to region, and further studies are required to demonstrate the relationship between these dietary habits and cultural beliefs and the risk of developing breast cancer. This study aims to discover the relationship between preventative dietary factors and rates of breast cancer among postmenopausal females in the Mecca region.

Methods: A case-control study was conducted at King Abdulla Medical City hospital in Mecca and included 432 Saudi female participants: 218 in a control group and 214 breast cancer patients. All participants were postmenopausal, around the same age, and all were ethnically Arab Saudis. Data was obtained using a self-administered validated questionnaire.

Results: Study results showed that a diet including 1-2 servings of legumes weekly, 1-5 servings of fish weekly, $1-5$ servings of dairy products daily, $3-5$ servings of fruits and vegetables daily, and more than one cup of black tea and coffee per day significantly $(p<0.05)$ reduced the risk of breast cancer.

Conclusion: This study supports the effect of a healthy diet incorporating dairy products, legumes, fish, fruits and vegetables, black tea, and coffee as a preventative factor against breast cancer in females from the Mecca region.

\section{Background}

Breast cancer is one of the leading causes of death worldwide, with 2.1 million newly diagnosed cases in 2018 [1]. In Saudi Arabia, breast cancer is the second-most common type of cancer, after rectal cancer, and is responsible for 3629 (14.8\%) new cases diagnosed in both genders. Breast cancer affects females more than males and represents $29.7 \%$ of newly diagnosed cancer cases in women [2]. In 2014, the tumor registry in King Faisal Specialist Hospital and Research Centre reported that breast cancer represented the highest percentage of cancer cases from 1975 to 2014 at 11.7\% [3]. The rapid increase in diagnoses in different age groups during the past few years makes breast cancer one of the most crucial topics to study in the medical field. About $5-10 \%$ of cancer cases are caused by genetic factors, while $90-95 \%$ are related to environmental factors and unhealthy lifestyle elements such as diet, obesity, and alcohol consumption [4].

The breast cancer rate in Saudi Arabia is considered high; we know that alcohol, obesity, a sedentary lifestyle, exogenous estrogen and progesterone, menarche at an early age ( $<12$ years old), previous surgeries or biopsies, previous mammography screenings, and never giving birth or breastfeeding are all risk factors for breast cancer $[5,6]$. A healthy diet and lifestyle have been shown to reduce the incidence of breast cancer and verifying the risk factors for breast cancer is of vital importance. Several studies have assessed the influence of lifestyle and nutrition on breast cancer [7, 8]. Fruits, vegetables, dairy products, and olive oil were found to be preventative against breast cancer [9]. Another study showed that 
following the Mediterranean diet rich in olive oil, fish, fruits, and vegetables reduced the risk of breast cancer [10]. A case-control study in Iran showed that a high level of vitamin $D$ in the fourth quartile of serum 25(OH)D decreased the risk of breast cancer [11]. On the other hand, high consumption of meat and fat increases the risk of breast cancer [12]. Regional differences in diet and lifestyle play a role in breast cancer development; women in Saudi Arabia have different dietary habits depending on the region they live in and its cultural beliefs. Further studies are required to compare the effect of dietary intake on breast cancer in different cultures. Therefore, this research aims to explore the causation or preventative factors for breast cancer in postmenopausal females from the Mecca region to more clearly understand the relationship between breast cancer and diet, focusing on the impact of a diet rich in dairy products, poultry, legumes, leafy vegetables, olive oil, fish, fruits and vegetables, coffee, tea, and low in meat and saturated fat.

\section{Material And Methods}

\section{Study design and setting}

This case-control study took place at King Abdullah Medical City Hospital in the Mecca region of Saudi Arabia from June 2014 to November 2016. This hospital is the biggest in the region, and the only center that provides screening and treatment of cancer locally.

\section{Participants}

For this study, a total of 432 female participants were recruited (214 cancer cases and 218 controls). Only Saudi postmenopausal women who were newly diagnosed with breast cancer and aged above 45 years old were included. A postmenopausal woman is defined as any woman who no longer has her period for at least a year. Diagnoses of breast cancer patients were confirmed via biopsy by the oncologist in the same hospital. To control for racial factors, only ethnically Arab women were invited to this study. Women in the control group were chosen from the hospital workers and patients' families or friends. They were selected from the same region and age range as the cases with a single year of age in match. Figure 1 is a flowchart showing inclusion and exclusion criteria for recruitment of participants.

\section{Data collection}

Data for this study were collected using convenience sampling and face-to-face interviews. Participants were asked to fill out a questionnaire supervised by a registered dietitian. The questionnaire recorded personal information and questions about dietary habits; a validated dietary questionnaire from the 2017 work of Azzeh et al. [13] was used. The questionnaire included questions about daily intake of foods such as fruits and vegetables, meat and processed meat, poultry, dairy products, and beverages such as coffee and black tea (Camellia sinensis). In the Saudi community, black tea is generally offered in an 80$\mathrm{ml}$ cup, while coffee is offered in a 50-ml standard cup. Other food categories including fish and seafood, olive oil, green leafy vegetables, and legumes were recorded weekly. Daily bread consumption and preferences for either white or whole wheat bread were also assessed. All participants were taught about 
the serving size for each food item prior to starting the questionnaire. The registered dietitian measured the height and weight of the participants using the Detecto physician's scale available at the hospital (Detecto, Webb City, Missouri, USA). Body mass index (BMI) was calculated by dividing weight in kilograms by height in meters squared.

\section{Statistical analysis}

Statistical tests in this study were completed using IBM SPSS statistics for Windows, version 20.0 (IBM Corp., Armonk, NY, USA); a p-value of $<0.05$ was set for the significant differences. A suitable test was used to decide the $\mathrm{p}$-value for each parameter. The data were arranged using a case-control status to verify the differences between the cases and the controls. To assess the risk factors related to breast cancer, the odds ratio (OR), $95 \%$ confidence intervals $(95 \% \mathrm{Cl})$, and $\beta$-coefficient were determined. All variables were adjusted according to the confounders described in Alsolami et al.'s paper [14], which were: BMI (continuous), employment, income, education level, family size, smoking, physical activity, cancer background, menstruation start, and contraceptives usage.

\section{Results}

The mean ages of the case and control groups were $57 \pm 7.3$ years old and $56.9 \pm 8.6$ years old, respectively. Socioeconomic factors were also taken into account: about $81.7 \%$ of the control group were employed, while $73.8 \%$ of the case group were unemployed. Almost half $(43.9 \%)$ of the case group participants had a low monthly income of $<5000$ SR compared to only $9.6 \%$ of the control group. Literacy was lower in the control group with $0.9 \%$ compared to $15 \%$ literacy in cancer cases. The case group had a noticeably larger family size compared to the control group. Menarche at an early age ( $<10$ years old) was remarkably higher in the case group as compared to the control group. No significant results were shown regarding marital status, family history of breast cancer, age of menopause, and breastfeeding duration in either control or case groups. The complete numbers and percentages for the baseline characteristics of the participants were published previously in Alsolami et al.'s research [14].

Table 1 records the dietary habits of all participants regarding the main food groups. No significant differences $(p>0.05)$ between groups were found in comparison with the number of meals consumed per day, poultry intake, and whole wheat vs white bread. However, fruits and vegetables (measured in servings per day), dairy products (servings per day), red and processed meat consumption (servings per day), and legumes (servings per week) showed significant results with $p<0.001$ between the two groups.

Table 2 presents dietary habits using a second group of common food items and drinks in the study groups. Results showed that there was a significant difference $(p<0.05)$ between the groups based on consumption of fish and seafood (measured in servings per week), leafy vegetables (servings per week), and olive oil (servings per week). Data measuring the consumption of black tea (cups per day) and coffee (cups per day) also showed a significant difference $(p<0.05)$ between the case and control groups. Only $8.3 \%$ of the control group ate $<1$ serving of fish and seafood every week compared to $29.9 \%$ of the case group. Around $3.7 \%$ of the case group consumed $<1$ serving per week of green leafy vegetables, while 
only $1.4 \%$ from the control group ate $<1$ serving per week. Participants in the control group consumed olive oil ( $p<0.001)$ more than the case group; $9.6 \%$ of the control group consumed $<1$ serving of olive oil per week, while $26.2 \%$ of the cancer cases consumed $<1$ serving of olive oil per week. About $56 \%$ and $36.4 \%$ of the control group and the case group, respectively, consumed 1-2 servings of olive oil per week. Participants with breast cancer tended to drink less black tea (in cups per day) compared to healthy participants ( $p<0.009$ ): $18.7 \%$ of the participants with breast cancer consumed $<1$ cup of tea per day, while $10.1 \%$ of the healthy subjects consumed the same amount of tea daily. Subjects from the control group also consumed more coffee: only 9 control subjects $(4.1 \%)$ drank $<1$ cup per day compared to 48 subjects $(22.4 \%)$ with breast cancer.

Potential dietary habits as related to breast cancer incidence are shown in Table 3. The consumption of 12 servings of dairy products per day was shown to be preventative against breast cancer with (OR = $0.178,95 \% \mathrm{Cl}=0.037-0.859, \mathrm{p}=0.032$ ), as was the consumption of $3-5$ servings of dairy products daily $(\mathrm{OR}=0.038,95 \% \mathrm{Cl}=0.004-0.372, \mathrm{p}=0.005)$. Results also showed a preventative effect based on consuming 1-2 servings of legumes per week $(O R=0.043,95 \% \mathrm{Cl}=0.01-0.191, p<0.001), 3-5$ servings of fruits and vegetables per day $(O R=0.161,95 \% \mathrm{Cl}=0.043-0.605, p=0.007), 1-2$ servings of fish and sea food per week $(\mathrm{OR}=0.211,95 \% \mathrm{Cl}=0.82-0.545, \mathrm{p}=0.001)$, and 3-5 servings of fish and sea food per week $(\mathrm{OR}=0.072,95 \% \mathrm{Cl}=0.202-0.265, \mathrm{p}<0.001)$. Drinking $1-2$ cups of tea $(\mathrm{OR}=0.06,95 \% \mathrm{Cl}=0.01-0.371$, $\mathrm{p}=0.002)$ or $3-5$ cups of tea daily was shown to reduce the incidence of breast cancer $(\mathrm{OR}=0.083,95 \% \mathrm{Cl}$ $=0.009-0.395, p=0.003)$. The daily intake of $1-2$ cups of coffee $(O R=0.159,95 \% \mathrm{Cl}=0.031-0.812$, $\mathrm{p}=0.027), 3-5$ cups of coffee $(\mathrm{OR}=0.083,95 \% \mathrm{Cl}=0.013-0.544, \mathrm{p}=0.009)$, or even more than 5 cups of coffee per day $(\mathrm{OR}=0.144,95 \% \mathrm{Cl}=0.028-0.736, \mathrm{p}=0.02)$ was shown to reduce the incidence of breast cancer.

\section{Discussion}

In Saudi Arabia, the rate of breast cancer ranges from three to eight confirmed cases for every 1000 patients. Breast cancer accounts for $14.8 \%$ of all cancers reported in Saudi nationals and about $29 \%$ of cancers among females of all ages [2]. It is incredibly important to assess the dietary factors associated with breast cancer in the Mecca region. This study showed that consuming healthy foods including black tea, coffee, fruits and vegetables, fish and seafood, legumes, and dairy products can be preventative factors against breast cancer.

Our study results showed that consuming one to five servings of dairy products daily, a major source of vitamin D for Saudi women, had up to a $96 \%$ preventative effect against breast cancer. Dairy products in Saudi Arabia are fortified with vitamin $\mathrm{D}$ which has been shown to reduce the risk of breast cancer by multiple mechanisms: either by promoting cell differentiation, decreasing cancer cell growth, stimulating cell death (apoptosis), or by reducing the formation of blood vessels in the tumor (angiogenesis) $[15,16]$. A recent review study supports our study findings that vitamin $D$ had an inverse relationship with breast cancer [17]. A descriptive study conducted in Saudi Arabia by AlFaris et al. [18], in contrast, demonstrated results comparing vitamin $\mathrm{D}$ and breast cancer that did not support our findings. This result can be 
explained by vitamin D deficiency among both the control group and the cancer group. The study also showed a relationship between symptoms of vitamin $D$ deficiency and breast density, where women with mild to moderate breast density appeared to develop more deficiency symptoms.

Dairy products are also a good source of calcium, which plays a role in reducing the risk of breast cancer. Although the exact mechanism is still unclear, a meta-analysis of eleven studies by Hidayat et al. [19] showed a connection between calcium intake and breast cancer. Calcium's ability to regulate the cells' apoptosis, proliferation, and differentiation makes it a significant preventative factor. Both calcium and vitamin $D$ were found to have anticarcinogenic effects in a review study by Cui [20]. On the other hand, a recent meta-analysis published in 2019 by Chen and his colleagues on the relationship between breast cancer and milk/yogurt intake did not support our results [21]. This discrepancy may be due to the number of servings consumed by the subjects of Chen et al.'s study [21] and the amount of vitamin D added to the dairy products. Some studies have indicated that environmental pollutants, growth factors, and the amount and type of fat in milk can raise the risk of breast cancer. Another relevant question is whether the cows producing the milk were given bovine growth hormone, which results in an increase in the insulin-like factor-1 in the milk and therefore causes malignant cells to proliferate [21].

Conjugated linoleic acid (CLA) in dairy products is considered a chemoprotective agent. CLA also has antioxidant and anti-inflammatory effects that can decrease the risk of developing breast cancer [22]. Research on the mechanism of CLA in reducing the risk of developing breast cancer is remarkably diverse, as described in a meta-analysis conducted by Zhou et al. [23] Another study by McCann et al. [24] did not support a clear correlation between CLA consumption and the development of breast cancer in pre- and postmenopausal women. They explained their result as being due to the high level of CLA consumption necessary for a preventative effect, as compared to the relatively low consumption by a typical test subject. Aro et al. [25] in their study found that breast cancer risk was higher in postmenopausal women who consumed a low amount of CLA from dairy products, but not in premenopausal women who consumed the same amount of CLA.

The study results also showed that the consumption of one to two servings of legumes per week had a negative association with breast cancer incidence. Various phytochemicals in legumes have an inhibitory effect on cell proliferation. Xu and Chang [26] comprehensively studied the effect of antioxidants and phytochemicals from different common types of legumes against nine different types of cancer including breast cancer, and they found that legumes are an outstanding source of natural antioxidants for the reduction of oxidative stress and cancer prevention. The fiber content in legumes was additionally found to inhibit the enterohepatic circulation of estrogen, leading to reduction of the circulating estrogen level and resulting in a reduction of breast cancer risk [27]. Fiber is also associated with decreasing cell mutation by binding with bile acid which is thought to promote cell proliferation [28].

Fruits and vegetables are rich sources of fibers that are known to protect against breast cancer. Women who have a daily intake of three to five servings of fruits and vegetables are $83.9 \%$ less likely to develop breast cancer. An important study by Farvid et al. [29] concluded that high fiber intake from fruits and 
vegetables reduced the risk of developing breast cancer in women. Antioxidants in fruits and vegetables have been shown to neutralize free radicals and prevent DNA damage that might lead to cancer [29]. Additionally, Naja et al. [28] concluded that the consumption of both fruits and vegetables reduces breast cancer risk. Many mechanisms could explain the preventative effect of fruit and vegetable consumption. Fiber content may bind to estrogen thereby inhibiting the estrogen enterohepatic reabsorption. Antioxidants in fruits and vegetables also reduce oxidative stress and inflammation by protecting the DNA from damage and by inducing detoxifying enzymes. Vitamin C, found especially in citrus fruits, has been shown to benefit the immune system, while vitamin $E$ and carotenoids have been found to have chemopreventive effects [29].

Women in Saudi communities eat seafood and fish regularly, especially on holidays. Our study indicates that consuming up to 5 servings of fish and seafood weekly reduces the risk of breast cancer by 78.9$92.8 \%$. The positive effect of fish consumption appears to be limited to certain common types of cancer including breast cancer [30]. Engeset et al. [31], however, found no evidence of an inverse correlation between overall fish intake and the risk of breast cancer. Fish are a known source of omega 3 fatty acids, or polyunsaturated fatty acids (PUFAs), which can reduce the risk of breast cancer [32]. Their study showed that PUFAs inhibit the epidermal growth factor receptor, which in turn reduces the proliferation of breast cancer.

Our study found that the consumption of coffee and black tea has a negative relationship to the development of breast cancer. In black tea, several antioxidant compounds and chemoprotective components are well known; catechins, particularly gallate epigallocatechin, exerted important antioxidant properties by decreasing the number of reactive oxygen species [33]. Other coffee components such as cafestol and kahweol are known to have antioxidant and anticarcinogenic effects. Kahweol restricts the proliferation of the breast cells and causes apoptosis; it also increases the synthesis of reactive oxygen species to produce cytotoxicity [34]. Another mechanism by which coffee reduces the risk of breast cancer is the inflammation, apoptosis, and other biological processes that reduce inflammatory markers circulating in the bloodstream, as well as insulin resistance which plays a role in developing breast cancer [33]. Yang et al. [35] explained the anticancerogenic mechanisms of black tea: its antioxidant effect protects the cell and DNA from being damaged by the free radicals. The phenolic compounds in coffee are known to have antioxidant, antimutagenic, and anticarcinogenic effects against several forms of cancer. A follow-up study by Ganmaa et al. [36] found a weak inverse link between caffeine consumption and the risk of postmenopausal breast cancer. Another article from Saudi Arabia supported our findings that caffeine content in coffee and tea provides effective prevention of breast tumor growth and/or recurrence [37].

A systematic review and meta-analysis published in 2015 indicated that the increased consumption of saturated fat positively affected breast cancer incidence [38]. Moreover, high consumption of meat has also been shown to increase the risk of developing breast cancer [39]. However, study results did not show a remarkable effect of high fat intake from meat and processed meat and the risk of breast cancer. 
It is noteworthy to perform further studies regarding this point considering the different types of meat and processed meat consumed locally.

This study is limited by the semiquantitative measurement of food intake, which is a common problem with studies that use food frequency questionnaires, as well as recall bias. This study was also limited by the regional sample collection, relatively small sample size, and recruitment of exclusively postmenopausal women for both case and control groups.

\section{Conclusion}

Our study in the Mecca region concluded that the consumption of coffee, black tea, fish and seafood, fruits and vegetables, legumes, and dairy products can have preventative effects against breast cancer. Dietary factors that did not show a significant effect on breast cancer incidence included the distinction between whole wheat and white bread, as well as the consumption of olive oil, red and processed meats, and leafy vegetables. It is recommended to perform additional studies using cohort study design in various regions of Saudi Arabia and with more participants.

\section{Abbreviations}

$x^{2}$ : Chi-squared, BMI: Body mass index, Cl: Confidence interval, KAMC: King Abdullah Medical City Hospital, OR: Odds ratio.

\section{Declarations}

\section{Ethics approval and consent to participate}

The study data was collected after the investigation was approved by the Institutional Review Board of Umm Al-Qura University (approval number AMSEC-2-20-5-2014), following the Declaration of Helsinki rules. Eligible women read and signed the consent form before starting the data collection.

\section{Acknowledgments}

The authors thank all staff members of King Abdullah Medical City Hospital in the Mecca region for their help and support.

\section{Consent to publish}

Not applicable.

\section{Availability of data and materials}

The datasets used and/or analyzed in this research cannot be publicly shared and they are available from the corresponding author on reasonable request. 


\section{Competing interests}

The authors declare that they have no competing interests in this work.

\section{Funding}

The authors received no financial support for this research.

\section{Authors' contributions}

F.S.A. conceived and designed the study. D.M.H., A.A.Q., K.J.G., W.F.A, A.A.A., and M.M.G. conducted research, provided research materials, and collected and organized data. H.M.A., M.H.A, M.M.H., and W.M.B. analyzed and interpreted data. All authors wrote initial and final draft of the article. All authors have critically reviewed and approved the final draft of the manuscript.

\section{References}

1. World Health Organization 2021. Breast cancer. Available from: https://www.who.int/cancer/prevention/diagnosis-screening/breast-cancer/en/. Accessed 19 Mar 2021.

2. Alqahtani WS, Almufareh NA, DomiatyDM, Albasher G, Alduwish MA, Huda Alkhalaf $H$, et al. Epidemiology of cancer in Saudi Arabia thru 2010-2019: a systematic review with constrained metaanalysis. AIMS Public Health. 2020;7:679-696.

3. KFSHRC (King Faisal specialist Hospital \& Research Center) 2014. Tumor Registry Annual Report. Available from: https://www.kfshrc.edu.sa/store/media/8ek.pdf. Accessed 22 Mar 2021.

4. Schwingshackl L, Schwedhelm C, Galbete C, Hoffmann G. Adherence to Mediterranean Diet and Risk of Cancer: An Updated Systematic Review and Meta-Analysis. 2017;9:1063.

5. AlQutub ST, Al-Raddadi RM, Bin Sadiq BM, Wafa S, Al-Gahmi A, Al-Amoudi S. Potential breast cancer risk factors among Saudi women aged $19-50$ years in Jeddah: a case-control study. J Egypt Public Health Assoc. 2013;88:165-170.

6. Khalis $M$, Chajès V, Moskal A, Biessy $C$, Huybrechts I, Rinaldi S, et al. Healthy lifestyle and breast cancer risk: A case-control study in Morocco. Cancer Epidemiol. 2019;58:160-166.

7. Grosso G, Bella F, Godos J, Sciacca S, Del Rio D, Ray S, et al. Possible role of diet in cancer: systematic review and multiple meta-analyses of dietary patterns, lifestyle factors, and cancer risk. Nutr Rev. 2017;75:405-419.

8. Xiao Y, Xia J, Li L, Ke Y, Cheng J, Xie Y, et al. Associations between dietary patterns and the risk of breast cancer: a systematic review and meta-analysis of observational studies. Breast Cancer Res. 2019;21:16.

9. Trichopoulou A, Bamia C, Lagiou P, Trichopoulos D. Conformity to traditional Mediterranean diet and breast cancer risk in the Greek EPIC (European Prospective Investigation into Cancer and Nutrition) 
cohort. Am J Clin Nutr. 2010;92:620-625.

10. Turati F, Carioli G, Bravi F, Ferraroni M, Serraino D, Montella M, et al. Mediterranean Diet and Breast Cancer Risk. Nutrients. 2018;10:326.

11. Jamshidinaeini Y, Akbari M, Abdollahi M, Ajami M, Davoodi S. Vitamin D Status and Risk of Breast Cancer in Iranian Women: A Case-Control Study. J Am Coll Nutr. 2016;35:639-646.

12. Wu J, Zeng R, Huang J, Li X, Zhang J, Ho J, et al. Dietary Protein Sources and Incidence of Breast Cancer: A Dose-Response Meta-Analysis of Prospective Studies. Nutrients. 2016;8:730.

13. Azzeh FS, Alshammari EM, Alazzeh AY, Abdelelah SJ, Ibrahim RD, El-Taani HA, et al. Healthy dietary patterns decrease the risk of colorectal cancer in the Mecca Region, Saudi Arabia: a case-control study. BMC Public Health. 2017;17:607.

14. Alsolami F, Azzeh F, Ghafouri K, Ghaith M, Almaimani R, Almasmoum H. Determinants of breast cancer in Saudi women from Makkah region: a case-control study (breast cancer risk factors among Saudi women). BMC Public Health. 2019;19:1554.

15. Deeb K, Trump D, Johnson C. Vitamin D signalling pathways in cancer: potential for anticancer therapeutics. Nat Rev Cancer. 2007;7:684-700.

16. Thorne J, Campbell M. The vitamin D receptor in cancer. Proc Nutr Soc P Nutr Soc. 2008;67:115-127.

17. Atoum M, Alzoughool F. Vitamin D and Breast Cancer: Latest Evidence and Future Steps. Breast Cancer. 2017;11:e117822341774981.

18. AlFaris N, ALkehayez N, AlMushawah F, Al Naeem A, AL-Amri N, Almudawah E. A descriptive study of vitamin $D$ and other nutritional factors in breast cancer patients in Saudi Arabia. Saudi Med J. 2018;39:564-571.

19. Hidayat K, Chen G, Zhang R, Du X, Zou S, Shi B, et al. Calcium intake and breast cancer risk: metaanalysis of prospective cohort studies. Br J Nutr. 2016;116:158-166.

20. Cui Y. Vitamin D, Calcium, and Breast Cancer Risk: A Review. Cancer Epidemiol Biomark Prev. 2006;15:1427-1437.

21. Chen L, Li M, Li H. Milk and yogurt intake and breast cancer risk. Medicine. 2019;98:e14900.

22. den Hartigh LJ. Conjugated Linoleic Acid Effects on Cancer, Obesity, and Atherosclerosis: A Review of Pre-Clinical and Human Trials with Current Perspectives. 2019;11:370.

23. Zhou Y, Wang T, Zhai S, Li W, Meng Q. Linoleic acid and breast cancer risk: a meta-analysis. Public Health Nutr. 2015;19:1457-1463.

24. McCann SE, Clement Ip, Margot M Ip, McGuire MK, Muti P, Edge S B, et al. Dietary intake of conjugated linoleic acids and risk of premenopausal and postmenopausal breast cancer, Western New York exposures and cancer study (WEB study). Cancer Epidemiol Biomark Prev. 2004;13:1480148.

25. Aro A, Männistö S, Salminen I, Ovaskainen ML, Kataja V, Uusitupa M. Inverse Association Between Dietary and Serum Conjugated Linoleic Acid and Risk of Breast Cancer in Postmenopausal Women. Nutr Cancer. 2000;38:151-157. 
26. Xu B, Chang S. Comparative study on antiproliferation properties and cellular antioxidant activities of commonly consumed food legumes against nine human cancer cell lines. Food Chem. 2012;134:1287-1296.

27. Sangaramoorthy M, Koo J, John E. Intake of bean fiber, beans, and grains and reduced risk of hormone receptor-negative breast cancer: the San Francisco Bay Area Breast Cancer Study. Cancer Med. 2018;7:2131-2144.

28. Naja F, Nasreddine L, Awada S, El Sayed Ahmad R, Hwalla N. Nutrition in the Prevention of Breast Cancer: A Middle Eastern Perspective. Front Public Health. 2019;7:316.

29. Zhang C, Ho S, Chen Y, Fu J, Cheng S, Lin F. Greater vegetable and fruit intake is associated with a lower risk of breast cancer among Chinese women. Int J Cancer.2009;125:181-188.

30. Lund E. Health benefits of seafood; Is it just the fatty acids? Food Chem. 2013;140:413-420.

31. Engeset D, Alsaker E, Lund E, Welch A, Khaw K T, Clavel-Chapelon F, et al. Fish consumption and breast cancer risk. The European Prospective Investigation into Cancer and Nutrition (EPIC). Int $J$ Cancer. 2006;119:175-182.

32. Nindrea R, Aryandono T, Lazuardi L, Dwiprahasto I. Protective Effect of Omega-3 Fatty Acids in Fish Consumption Against Breast Cancer in Asian Patients: A Meta-Analysis. Asian Pac J. 2019;20:327332.

33. Oh J, Sandin S, Ström P, Löf M, Adami H, Weiderpass E. Prospective study of breast cancer in relation to coffee, tea and caffeine in Sweden.Int J Cancer. 2015;137:1979-1989.

34. Nehlig A, Reix N, Arbogast P, Mathelin C. Coffee consumption and breast cancer risk: a narrative review in the general population and in different subtypes of breast cancer. Eur J Nutr. 2021;60:11971235.

35. Yang C, Lambert J, Sang S. Antioxidative and anti-carcinogenic activities of tea polyphenols. Arch Toxicol. 2008;83:11-21.

36. Ganmaa D, Willett W, Li T, Feskanich D, van Dam R, Lopez-Garcia E, et al. Coffee, tea, caffeine and risk of breast cancer: A 22-year follow-up. Int J Cancer. 2008;122:2071-2076.

37. Al-Ansari M, Aboussekhra A. Caffeine Mediates Sustained Inactivation of Breast Cancer-Associated Myofibroblasts via Up-Regulation of Tumor Suppressor Genes. PLOS ONE. 2014;9:e90907.

38. Brennan S, Woodside J, Lunny P, Cardwell C, Cantwell M. Dietary fat and breast cancer mortality: A systematic review and meta-analysis. Crit Rev Food Sci Nutr. 2015;57:1999-2008.

39. Boldo E, Castelló A, Aragonés N, Amiano P, Pérez-Gómez B, Castaño-Vinyals G, et al. Meat intake, methods and degrees of cooking and breast cancer risk in the MCC-Spain study. Maturitas. 2018;110:62-70.

\section{Tables}

Table 1 Dietary habits for the main food groups between case and control participants 


\begin{tabular}{|c|c|c|c|}
\hline Parameter & $\begin{array}{l}\text { Control } \\
(n=218)\end{array}$ & $\begin{array}{l}\text { Case } \\
(n=214)\end{array}$ & $\mathrm{p}$-value \\
\hline \multicolumn{4}{|l|}{ Meals/day } \\
\hline$<2$ & $57(26.1 \%)$ & $70(32.7 \%)$ & \\
\hline$>3-5$ & $161(73.9 \%)$ & $144(67.3 \%)$ & 0.134 \\
\hline \multicolumn{4}{|c|}{$\begin{array}{l}\text { Fruits and vegetables } \\
\text { (servings/day) }\end{array}$} \\
\hline$<1$ & $24(11 \%)$ & $38(17.8 \%)$ & \multirow[t]{4}{*}{$<0.001$} \\
\hline $1-2$ & $150(68.8 \%)$ & $158(73.8 \%)$ & \\
\hline $3-5$ & $42(19.3 \%)$ & $14(6.5 \%)$ & \\
\hline$>5$ & $2(0.9 \%)$ & $4(1.9 \%)$ & \\
\hline \multicolumn{4}{|c|}{ Dairy products (servings/day) } \\
\hline$<1$ & $4(1.8 \%)$ & $58(27.1 \%)$ & \multirow[t]{4}{*}{$<0.001$} \\
\hline $1-2$ & $193(88.5 \%)$ & $134(62.6 \%)$ & \\
\hline $3-5$ & $19(8.7 \%)$ & $16(7.5 \%)$ & \\
\hline$>5$ & $2(0.9 \%)$ & $6(2.8 \%)$ & \\
\hline \multicolumn{4}{|c|}{ Red and processed meat (servings/day) } \\
\hline$<1$ & $14(6.4 \%)$ & $16(7.5 \%)$ & \multirow[t]{4}{*}{$<0.001$} \\
\hline $1-2$ & $152(69.7 \%)$ & $94(43.9 \%)$ & \\
\hline $3-5$ & $35(16.1 \%)$ & $48(22.4 \%)$ & \\
\hline$>5$ & $17(7.8 \%)$ & $56(26.2 \%)$ & \\
\hline \multicolumn{4}{|c|}{$\begin{array}{l}\text { Poultry } \\
\text { (servings/day) }\end{array}$} \\
\hline$<1$ & $24(11 \%)$ & $28(13.1 \%)$ & \multirow[t]{4}{*}{0.093} \\
\hline $1-2$ & 147 (67.4\%) & $158(73.8 \%)$ & \\
\hline $3-5$ & $40(18.3 \%)$ & $26(12.1 \%)$ & \\
\hline$>5$ & $7(3.2 \%)$ & $2(0.9 \%)$ & \\
\hline \multicolumn{4}{|c|}{ Legumes (servings/week) } \\
\hline$<1$ & $10(4.6 \%)$ & $40(18.7 \%)$ & \multirow[t]{2}{*}{$<0.001$} \\
\hline $1-2$ & $171(78.4 \%)$ & $118(55.1 \%)$ & \\
\hline
\end{tabular}




\begin{tabular}{|llll|}
$3-5$ & $33(15.1 \%)$ & $48(22.4 \%)$ & \\
\hline 5 & $4(1.8 \%)$ & $8(3.7 \%)$ & \\
\hline Bread type & & & \\
\hline White & $103(47.2 \%)$ & $110(51.4 \%)$ & 0.388 \\
Brown & $115(52.8 \%)$ & $104(48.6 \%)$ & \\
\hline
\end{tabular}

Values are expressed as frequency (\%).

p-values are obtained by $x^{2}$ test.

Table 2 Dietary habits of the study groups related to common foods and drinks 


\begin{tabular}{|c|c|c|c|}
\hline Parameter & $\begin{array}{l}\text { Control } \\
(n=218)\end{array}$ & $\begin{array}{l}\text { Case } \\
(n=214)\end{array}$ & p-value \\
\hline \multicolumn{4}{|l|}{$\begin{array}{l}\text { Fish and seafood } \\
\text { (servings/week) }\end{array}$} \\
\hline$<1$ & $18(8.3 \%)$ & $64(29.9 \%)$ & $<0.001$ \\
\hline $1-2$ & $153(70.2 \%)$ & $133(62.1 \%)$ & \\
\hline $3-5$ & $44(20.2 \%)$ & $13(6.1 \%)$ & \\
\hline$>5$ & $3(1.4 \%)$ & $4(1.9 \%)$ & \\
\hline Leafy vegetables (servings/week) & & & $<0.001$ \\
\hline$<1$ & $3(1.4 \%)$ & $8(3.7 \%)$ & \\
\hline $1-2$ & $140(64.2 \%)$ & $126(58.9 \%)$ & \\
\hline $3-5$ & $53(24.3 \%)$ & $32(15 \%)$ & \\
\hline$>5$ & $22(10.1 \%)$ & $48(22.4 \%)$ & \\
\hline \multicolumn{4}{|l|}{ Olive oil (servings/week) } \\
\hline$<1$ & $21(9.6 \%)$ & $56(26.2 \%)$ & $<0.001$ \\
\hline $1-2$ & $122(56 \%)$ & $78(36.4 \%)$ & \\
\hline $3-5$ & $40(18.3 \%)$ & $40(18.7 \%)$ & \\
\hline$>5$ & $35(16.1 \%)$ & $40(18.7 \%)$ & \\
\hline \multicolumn{4}{|l|}{ Black tea (cup/day) } \\
\hline$<1$ & $22(10.1 \%)$ & $40(18.7 \%)$ & 0.009 \\
\hline $1-2$ & $45(20.6 \%)$ & $48(22.4 \%)$ & \\
\hline $3-5$ & $19(8.7 \%)$ & $7(3.3 \%)$ & \\
\hline$>5$ & $132(60.6 \%)$ & $119(55.6 \%)$ & \\
\hline \multicolumn{4}{|l|}{ Coffee (cup/day) } \\
\hline$<1$ & $9(4.1 \%)$ & $48(22.4 \%)$ & $<0.001$ \\
\hline $1-2$ & 63 (28.9\%) & $86(40.2 \%)$ & \\
\hline $3-5$ & 29 (13.3\%) & $11(5.1 \%)$ & \\
\hline$>5$ & 117 (53.7\%) & 69 (32.3\%) & \\
\hline
\end{tabular}

Values are expressed as frequency (\%). 
p-values are obtained by $x^{2}$ test.

Table 3 Potential dietary habits as predictors for breast cancer 


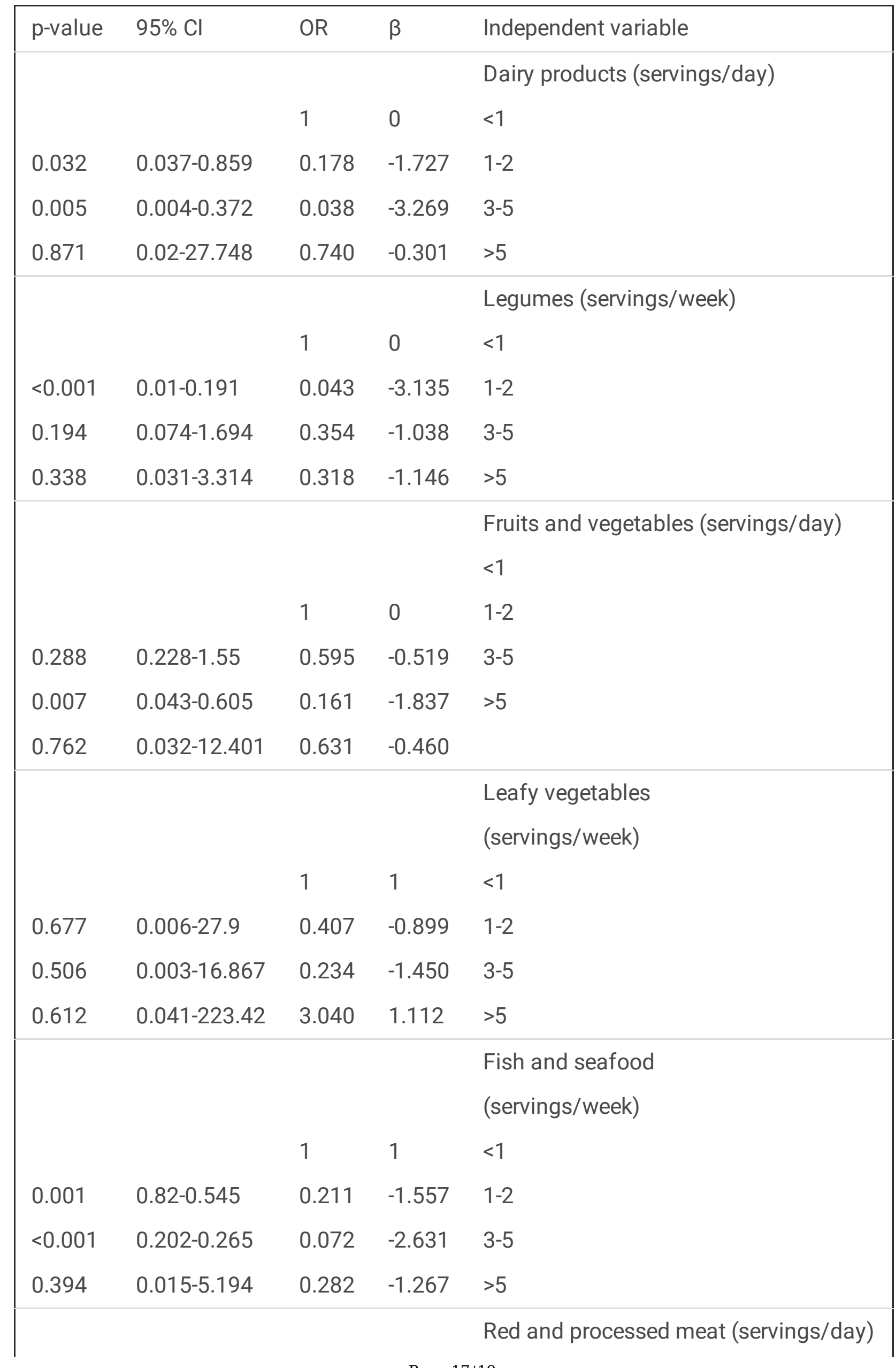




\begin{tabular}{|lllll|} 
& & 1 & 1 & $<1$ \\
0.811 & $0.137-4.746$ & 0.806 & -0.216 & $1-2$ \\
0.691 & $0.222-9.695$ & 1.466 & 0.383 & $3-5$ \\
0.303 & $0.405-18.280$ & 2.72 & 1.001 & $>5$ \\
& & & & Olive oil (servings/week) \\
& & 1 & 0 & $<1$ \\
0.478 & $0.218-2.042$ & 0.667 & -0.405 & $1-2$ \\
0.256 & $0.574-8.014$ & 2.145 & 0.763 & $3-5$ \\
0.517 & $0.426-5.454$ & 1.524 & 0.422 & $>5$ \\
\hline & & & & Black tea (cups/day) \\
& & 1 & 0 & $<1$ \\
0.002 & $0.01-0.371$ & 0.06 & -2.811 & $1-2$ \\
0.003 & $0.009-0.395$ & 0.06 & -2.820 & $3-5$ \\
0.079 & $0.106-1.131$ & 0.346 & -1.062 & $>5$ \\
0.027 & $0.031-0.812$ & 0.159 & -1.842 & $1-2$ \\
0.009 & $0.013-0.544$ & 0.083 & -2.487 & $3-5$ \\
0.02 & $0.028-0.736$ & 0.144 & -1.940 & $>5$ \\
\hline & & & & Coffee (cups/day) \\
\hline & & & & $<1$ \\
\hline
\end{tabular}

The reference is the control group.

All variables were adjusted according to the confounders described in Alsolami et al.'s paper. ${ }^{14}$ Abbreviations: $\beta$ : beta coefficient; $\mathrm{Cl}$ : confidence interval; OR: odds ratio.

\section{Figures}




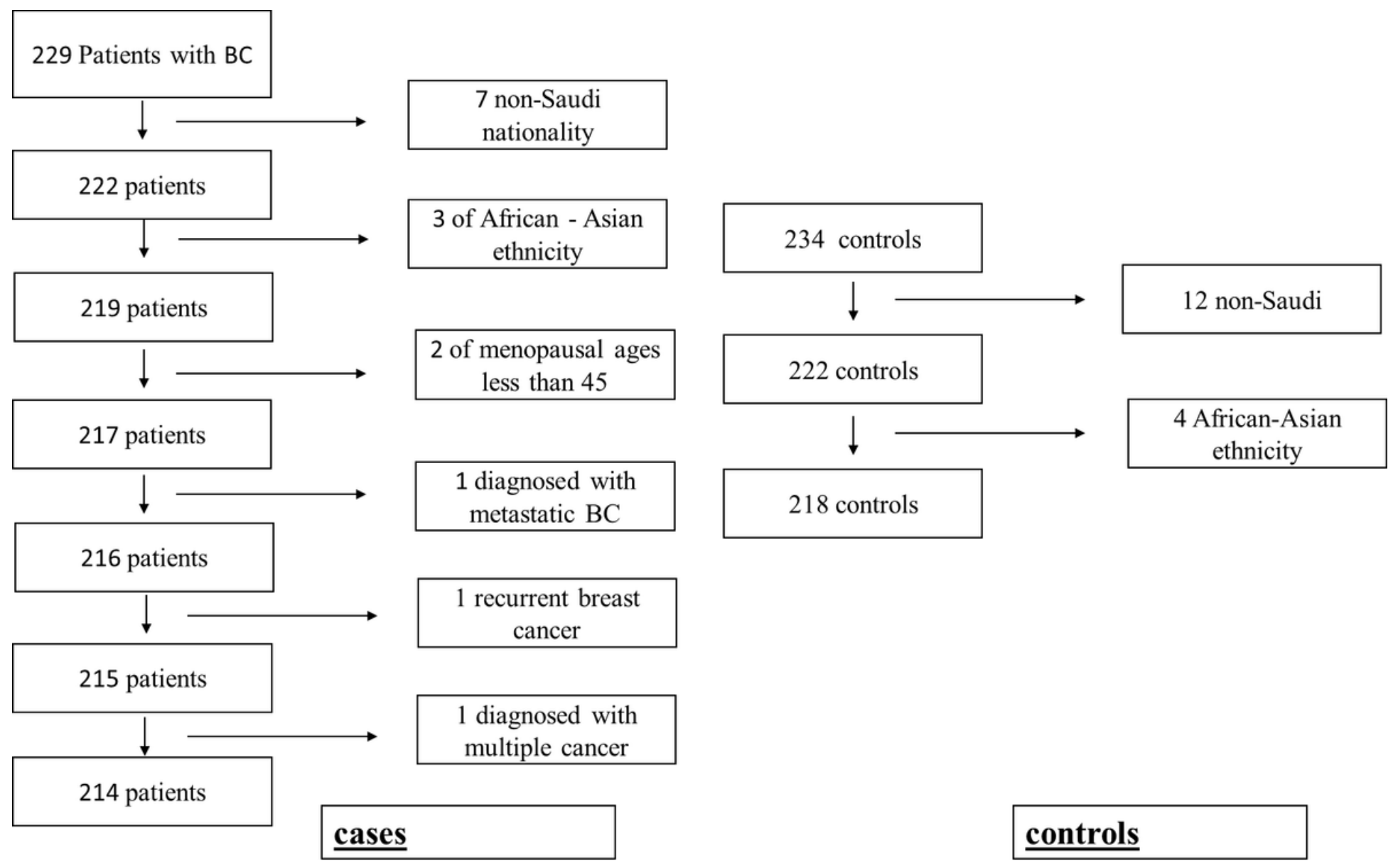

Figure 1

Flowchart for recruiting cancer patients and control group participants. 